\title{
Undiagnosed Anterior Cranial Fossa Dural Arteriovenous Fistula with Intracranial Hematoma: Case Report and Review of the Literature about Its Natural History
}

\author{
Takashi Yamaguchi*, Satsuki Miyata, Toshihiro Mashiko, Eiju Watanabe \\ Department of Neurosurgery, Jichi Medical University, Shimotsuke, Japan \\ Email: ${ }^{*}$ takashiy@jichi.ac.jp
}

Received 28 March 2015; accepted 17 April 2015; published 22 April 2015

Copyright (C) 2015 by authors and Scientific Research Publishing Inc.

This work is licensed under the Creative Commons Attribution International License (CC BY). http://creativecommons.org/licenses/by/4.0/

(c) (i) Open Access

\begin{abstract}
Dural arteriovenous fistulas (dAVFs) of an anterior cranial fossa are rare. Because of the high risk of intracranial hemorrhage and relatively easy access for direct surgery, aggressive treatment has been recommended. The natural history of anterior cranial fossa dAVFs (ACF dAVFs) is unclear in spite of many reports for the natural history of general dAVFs. To treat ACF dAVFs, direct surgery has traditionally been performed and endovascular surgery has recently been introduced. A 74year-old man was transferred with severe consciousness disturbance and presented with devastating intracerebral hemorrhage on the CT scan. Digital subtraction angiography revealed the ACF dAVFs with a large venous pouch. The patient received direct surgery, nevertheless he became vegetative state. Later on, a smaller venous pouch was recognized on the CT scan when he had suffered from the thalamic hemorrhage sixteen months before. There are twelve cases including our case which was treated for a certain period and documented in detail. Eleven of twelve cases were asymptomatic. Three of the six cases with a venous pouch had some events possibly related to the disease, though none of the six cases without a venous pouch had any events during observation. In conclusion, an ACF dAVF with a venous pouch should be treated by direct surgery or endovascular surgery even if it is incidentally found. By contrast, careful observation might be a possible therapeutic option for an ACF dAVF without a venous pouch if there is mild reflux flow.
\end{abstract}

\section{Keywords}

Dural Arteriovenous Fistula, Anterior Cranial Fossa, Natural History, Venous Pouch, Intracranial Hemorrhage

\footnotetext{
"Corresponding author.
} 


\section{Introduction}

Dural arteriovenous fistulas (dAVFs) comprise approximately 10\% - 15\% of all intracranial arteriovenous malformations [1] [2]. Most of them are located in the posterior fossa or in the region of the cavernous sinus [3]-[5]. Anterior cranial fossa (ACF) dAVF, also called as ethmoidal dAVF, was first described by Lepoire et al. in 1963 [6] and is relatively rare. These dAVFs account for about 5.8\% of all intracranial dAVFs [7] and have suggested a distinct subgroup for the typical features including a strong male predominance and a high incidence of hemorrhage. ACF dAVF generally has the typical pattern of venous drainage, with the cortical drainage vein draining into the superior sagittal sinus and often a venous sac along the abnormal vein. These fragile venous systems carry high risk of disruption and are considered to be responsible for intracranial hemorrhage [8]-[12]. Since the dAVFs of the anterior cranial fossa should be treated even if asymptomatic at the time of diagnosis due to a higher risk of hemorrhage or neurological deficits [13]. In consequence, there are few reports about the natural history of ACF dAVFs despite many reports for general dAVFs. In this report, we presented a case of an ACF dAVF with severe intracranial hemorrhage whose venous pouch was not recognized at the time of the thalamic hemorrhage sixteen months before, and reviewed the literature to clarify its natural history.

\section{Case Report}

A 74-year-old man was transferred to our institute with severe impairment of consciousness. On admission, his Glasgow Coma Scale was 4 (E1V1M2) and he exhibited partial loss of brain stem reflexes. CT scan showed a large hematoma in the right frontal lobe with subdural and intraventricular hemorrhage. A more noteworthy finding was that suspicious vascular dilatation was located next to the intracerebral hematoma (Figure 1). Digital subtraction angiography (DSA) disclosed the presence of the dural arteriovenous fistula (dAVF) at the right anterior cranial fossa and fed mostly by the bilateral anterior ethomoidal arteries and partially by the falcine branch of the left middle meningeal artery, and the dAVF drained into the frontal cortical vein with a large venous pouch which coursed to the superior sagittal sinus (Figure 2).

During angiography, his bilateral pupils were dilated. He immediately received right frontal craniotomy and evacuation of the hematoma. On opening the dura mater, the intracerebral hematoma penetrated the frontal lobe and arterial bleeding occurred. After removing the hematoma, it was obvious that his arterial bleeding was caused by a venous pouch. The venous pouch and the dilated drainer were occluded by electrocoagulation with obliteration of the fistula.

Later on, we had a chance to recheck the CT scan which had been taken 16 months previously when the patient had suffered from a right thalamic hemorrhage. It revealed that the existence of the venous pouch at the right anterior cranial fossa and that the pouch had been smaller than in the onset of the massive hemorrhage (Figure 3). Post-operative DSA showed the dAVF was completely occluded (Figure 4). The patient survived after the surgery but remained in a vegetative state.
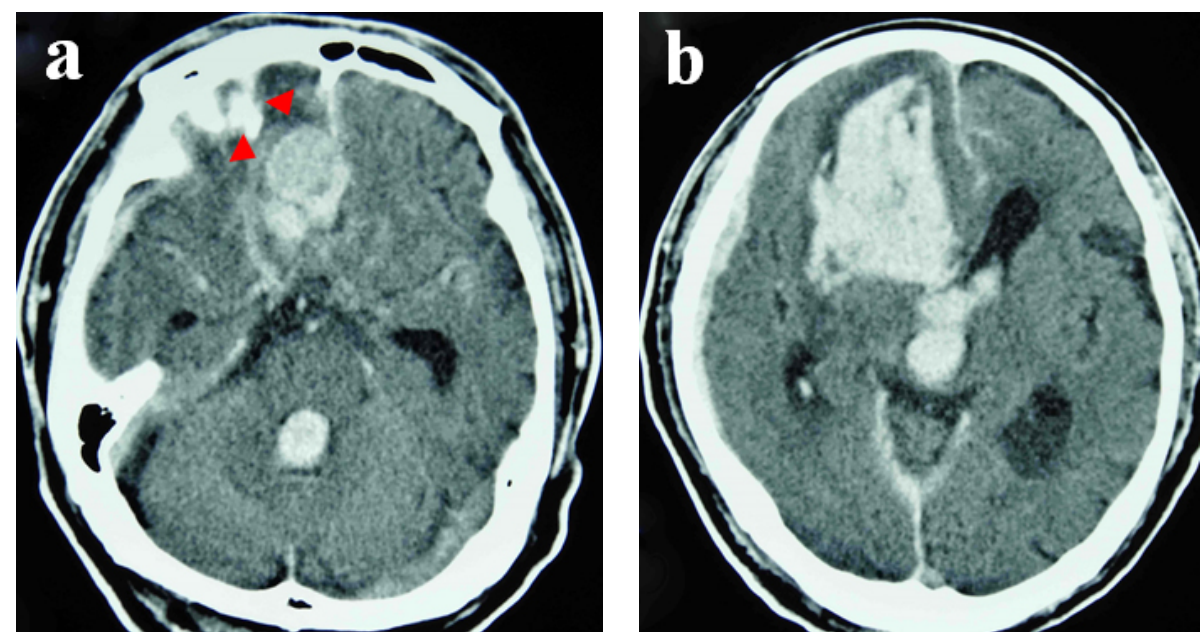

Figure 1. CT scans without contrast medium (a), (b) revealing an intracerebral hematoma with subdural and intraventricular hemorrhage and suspicious vascular dilatation (arrowheads). 


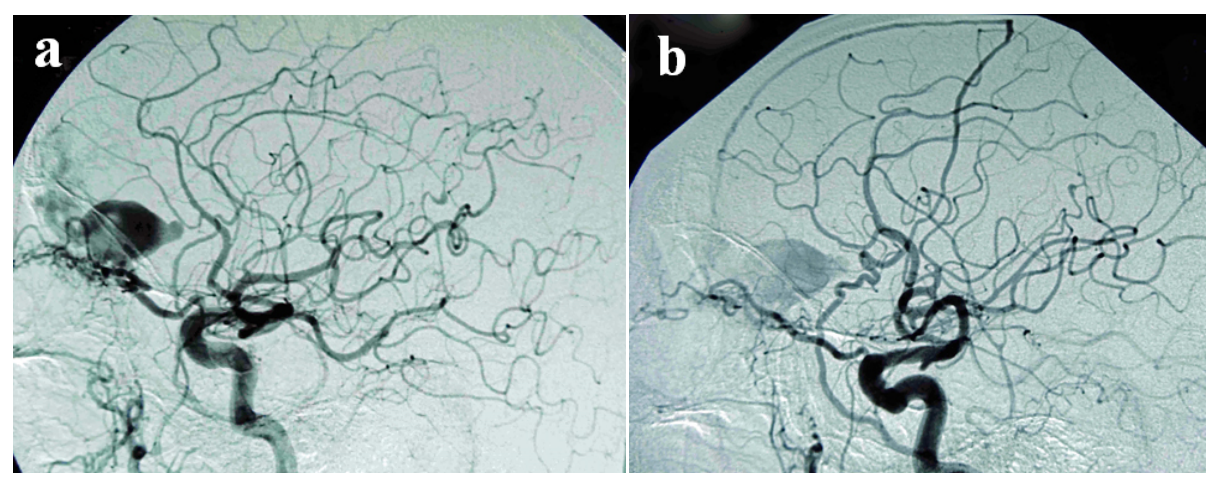

Figure 2. Left (a) and right (b) carotid angiograms showing dAVF of the anterior cranial fossa fed by the bilateral ethmoidal arteries and the falcine branch of the left middle meningeal artery, furthermore demonstrating the cortical venous drainage and the huge venous pouch.
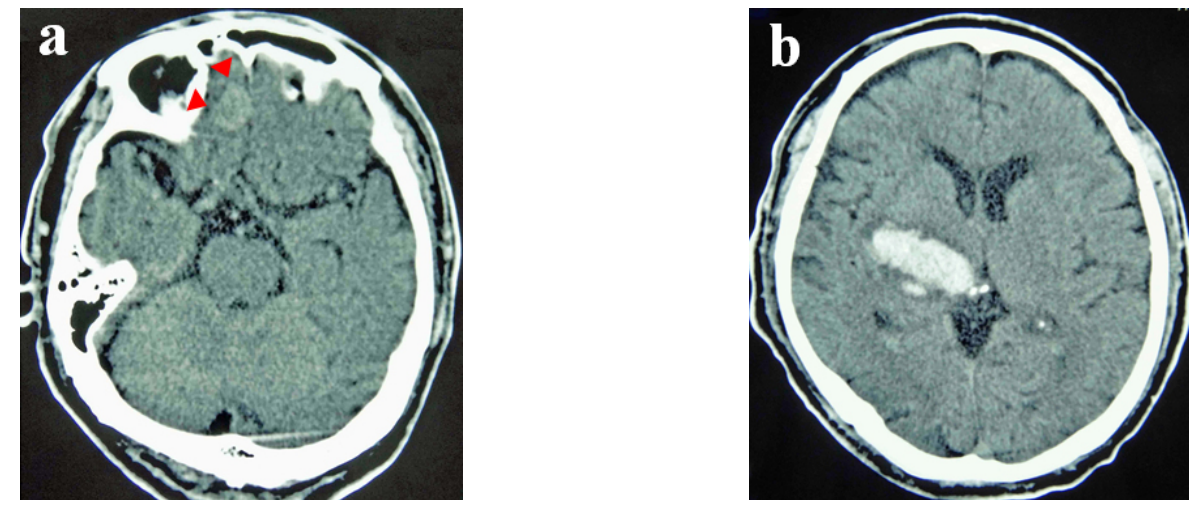

Figure 3. CT scans without contrast medium (a), (b) obtained 16 months before showing right thalamic hemorrhage with the smaller venous pouch in the right anterior cranial fossa (arrowheads).
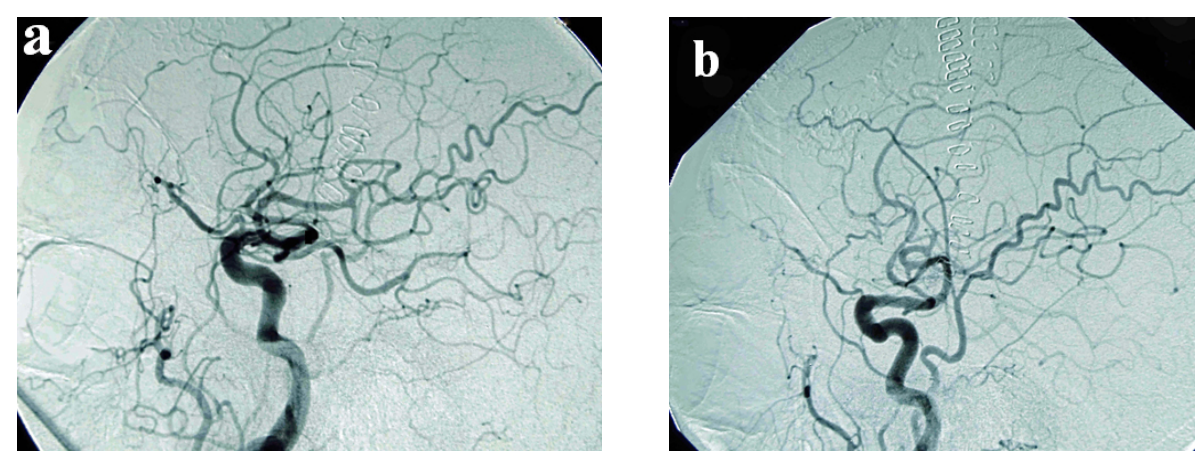

Figure 4. Postoperative left (a) and right (b) carotid angiograms demonstrating no residual dAVF.

\section{Discussion}

Dural arteriovenous fistulas (dAVFs) of an anterior cranial fossa have several clinical characteristics. They are relatively rare, and have a male predominance (80\% - 85\%) [14], an elderly onset [15], almost always drain via pial veins, and are associated with a high incidence of intracranial hemorrhage, ranging from $62 \%$ to $91 \%$ [7] [9]. With respect to the evidence of male predominance and the late onset, Geibprasert et al. proposed a new embryological classification of dAVFs. They suggested that fistulas located in the lateral epidural space, which included the lamina cribrosaossisethmoidalis, were strongly predominant in men, whereas those located in the ventral epidural space, which included the basioccipital bone, the sigmoid sinus, the petrosal pyramid and the 
basisphenoid, were more common in women. Furthermore, the shunt of the lateral epidural group was also present in elder subjects and always accompanied by cortical venous reflux (CVR) [16].

As for general dAVFs, Awad et al. reported that leptomeningeal venous drainage, venous pouch, and galenic drainage correlated significantly $(p<0.05)$ with aggressive neurological presentation [17]. van Dijk et al. mentioned persistence of the cortical venous reflux (CVR) in cranial dAVFs yielded an annual mortality rate of $10.4 \%$ and that the annual risk for hemorrhage or nonhemorrhage neurological deficit during follow-up was $8.1 \%$ or $6.9 \%$, respectively, resulting in an annual event rate of $15.0 \%$, so that these numbers mandated prompt diagnosis and treatment of these aggressive lesions [18]. On the other hand, Strom et al. concluded annual event rates of asymptomatic dAVFs with CVR were $1.4 \%$ and had less aggressive clinical course than symptomatic dAVFs with CVR [19].

The natural history of an anterior cranial fossa (ACF) dAVF is not fully understood because direct surgery have been strongly recommended due to the high risk of bleeding and relatively easy access to disconnect the fistula [20]. There are few cases histories of untreated ACF dAVFs. Twelve cases of the ACF dAVFs including our case that were observed for a certain period and documented in detail have been reported (Table 1) [14] [20]-[27]. The mean age at radiological recognition was 62.8 years old with a range between 47 and 76 years old, and only one case showed small intracranial hemorrhage at diagnosis, that is, eleven cases were found as asymptomatic ACF dAVFs. Almost all feeders were ethmoidal arteries arisen from ophthalmic arteries and draining frontal pial veins flowed into the superior sagittal sinus in eleven cases. Three cases with events possibly related to the disease during the follow-up period accompanied an obvious venous pouch (Cognard Type IV [28]). Two of the three cases presented severe intracerebral hemorrhage and one showed an enlargement of the venous pouch. Nine cases were performed curative operations or discontinued follow-up without any related event. As a result, half of Cognard Type IV had bleeding or very close to bleeding although all of Cognard Type III [28] had no bleeding during observation.

In our case, the patients had developed a thalamic hemorrhage and a venous pouch had unfortunately been overlooked, finally bleeding from the venous pouch resulted in serious neurological deficits. The draining pial vein flowed into the superior sagittal sinus, not the cavernous sinus or other deep venous systems. Therefore, his ACF dAVF was considered to be no relation to the thalamic hemorrhage and asymptomatic at the time.

It is well known that direct surgery to disconnect the fistula near a cribriform plate is sufficient and relatively safe. Because of less morbidity of direct surgery and poor outcome after bleeding, direct surgery has been strongly recommended. Until recently, transarterial embolization via the ophthalmic artery or transvenous embolization via draining vein independent of sinuses was at risk of retinal ischemic complications or very difficult to

Table 1. Clinical features of 12 patients with observed anterior cranial fossa dAVFs.

\begin{tabular}{|c|c|c|c|c|c|c|c|c|c|}
\hline Case & Author, Year & Age/Sex & Symptom & Feeder & Draining System & VP & FU & Event & GOS \\
\hline 1 & Bitoh, 1981 & $61 / \mathrm{M}$ & $(-)$ & ECA & $\mathrm{CV} \rightarrow \mathrm{SSS}$ & $(+)$ & 4 mo & op & MD \\
\hline 2 & Yamasaki, 1995 & $76 / \mathrm{M}$ & $(-)$ & $\mathrm{EA}>\mathrm{ECA}$ & $\mathrm{CV} \rightarrow \mathrm{SSS}$ & $(+)$ & $1 \mathrm{y}$ & censored & GR \\
\hline 3 & Ishikawa, 1997 & $65 / M$ & $(-)$ & EA & $\mathrm{CV} \rightarrow \mathrm{SSS}$ & $(-)$ & $5 y$ & op & GR \\
\hline 4 & Im, 2004 & $68 / \mathrm{M}$ & $(-)$ & ECA & $\mathrm{CV} \rightarrow \mathrm{SSS}$ & $(+)$, small & $7 y$ & Enlargement of VP & GR \\
\hline 5 & Jamous, 2004 & $47 / \mathrm{M}$ & small ICH & EA & $\mathrm{CV} \rightarrow \mathrm{SSS}$ & $(-)$ & $10 \mathrm{y}$ & censored & GR \\
\hline 6 & & $71 / \mathrm{M}$ & $(-)$ & EA & $\mathrm{CV} \rightarrow \mathrm{SSS}$ & $(-)$ & $2 \mathrm{y}$ & censored & GR \\
\hline 7 & & $60 / \mathrm{M}$ & $(-)$ & EA & $\mathrm{CV} \rightarrow \mathrm{SSS}$ & $(-)$ & $3 y$ & censored & GR \\
\hline 8 & Murakami, 2005 & $52 / \mathrm{M}$ & $(-)$ & EA & $\mathrm{CV} \rightarrow \mathrm{SSS}$ & $(-)$ & $3 y$ & censored & GR \\
\hline 9 & Deshmukh, 2005 & $50 / \mathrm{M}$ & $(-)$ & EA & $\mathrm{CV} \rightarrow \mathrm{SSS}$ & $(-)$ & 6 mo & op & GR \\
\hline 10 & Hashiguchi, 2007 & $67 / M$ & $(-)$ & $\mathrm{ECA}>\mathrm{EA}$ & $\mathrm{CV} \rightarrow \mathrm{CS}$ & $(+)$ & $4 y$ & $\mathrm{ICH}$ & SD \\
\hline 11 & Tanei, 2008 & $63 / \mathrm{M}$ & $(-)$ & EA & $\mathrm{CV} \rightarrow \mathrm{SSS}$ & $(+)$, small & $3 y$ & censored & GR \\
\hline 12 & Present case, 2015 & $74 / \mathrm{M}$ & $(-)$ & $\mathrm{EA}>\mathrm{ECA}$ & $\mathrm{CV} \rightarrow \mathrm{SSS}$ & $(+)$ & $16 \mathrm{mo}$ & $\mathrm{ICH}$ & VS \\
\hline
\end{tabular}

VP: venous pouch; FU: follow up period; GOS: Glasgow Outcome Scale; M: male; ICH: intracerebral hemorrhage; ECA: external carotid artery; EA: ethomoidal artery; CV: cortical vein; SSS: superior sagittal sinus; CS: cavernous sinus; mo: month; y: year; op: operation; MD: moderate disability; GR: good recovery; SD: severe disability; VS: vegetative state. 
access. There are several successful reports of transarterial or transvenous embolization for the ACF dAVFs [29]-[32]. Endovascular treatment can be selected in some cases.

For an ACF dAVF with a venous pouch, direct surgery or endovascular surgery must be considered regardless of whether symptoms are present or not because of the high risk of bleeding. But for an ACF dAVF without a venous pouch, therapeutic decision making should be based on radiological findings since Cognard Type III ACF dAVF might be less dangerous.

\section{Conclusion}

We experienced the case of the anterior cranial fossa dural arteriovenous fistula (ACF dAVF) which resulted in vegetative state because its venous pouch had been overlooked. By reviewing the literature, it is clarified that an ACF dAVF with a venous pouch (Cognard type IV) should be treated by direct surgery or endovascular surgery as previously believed even if it is incidentally found. Conversely, careful observation might be one possible therapeutic option for an anterior cranial fossa dAVF without a venous pouch (Cognard type III) in the case of mild reflux flow. In conclusion, it is important to circumspectly decide the strategy for ACF dAVFs with consideration of the symptoms, the existence of a venous pouch, and the amount of venous reflux.

\section{Disclosure}

The authors declare that they have no conflict of interest and have signed informed consent forms from the patient's relatives before submitting to the Open Journal of Modern Neurosurgery.

\section{References}

[1] Houser, O.W., Baker Jr., H.L., Rhoton Jr., A.L. and Okazaki, H. (1972) Intracranial Dural Arteriovenous Malformations. Radiology, 105, 55-64. http://dx.doi.org/10.1148/105.1.55

[2] Ohta, T. and Kajikawa, H. (1978) Dural Arteriovenous Malformation (Author's Transl). Neurologia Medico-Chirurgica (Tokyo), 18, 439-472 (in Japanese).

[3] Newton, T.H., Weidner, W. and Greitz, T. (1968) Dural Arteriovenous Malformation in the Posterior Fossa. Radiology, 90, 27-35. http://dx.doi.org/10.1148/90.1.27

[4] Malik, G.M., Pearce, J.E., Ausman, J.I. and Mehta, B. (1984) Dural Arteriovenous Malformations and Intracranial Hemorrhage. Neurosurgery, 15, 332-339. http://dx.doi.org/10.1227/00006123-198409000-00007

[5] Lasjaunias, P., Manelfe, C. and Chiu, M. (1986) Angiographic Architecture of Intracranial Vascular Malformations and Fistulas_-Pretherapeutic Aspects. Neurosurgical Review, 9, 253-263. http://dx.doi.org/10.1007/BF01743632

[6] Lepoire, J., Montaut, J., Bouchot, M. and Laxenaire, M. (1963) Intrafrontal Arteriovenous Aneurysms Vascularized by the Anterior Ethmoidal Artery. Apropos of 3 Cases. Neuro-Chirurgie, 9, 159-166 (in French).

[7] King, W.A. (1993) Anterior Fossa Dural Arteriovenous Malformation. In: Award, I.A. and Barrow, D.L., Eds., Dural Arteriovenous Malformations, American Association of Neurological Surgeons, Park Ridge, 105-106.

[8] Gliemroth, J., Nowak, G. and Arnold, H. (1999) Dural Arteriovenous Malformation in the Anterior Cranial Fossa. Clinical Neurology Neurosurgery, 101, 37-43. http://dx.doi.org/10.1016/S0303-8467(98)00075-4

[9] Halbach, V.V., Higashida, R.T., Hieshima, G.B., Charles, B.W., Stanley, L.B. and Christopher, F.D. (1990) Dural Arteriovenous Fistulas Supplied by Ethmoidal Arteries. Neurosurgery, 26, 816-823. http://dx.doi.org/10.1227/00006123-199005000-00014

[10] Kaplan, S.S., Ogilvy, C.S. and Crowell, R.M. (1994) Incidentally Discovered Arteriovenous Malformation of the Anterior Fossa Dura. British Journal of Neurosurgery, 8, 755-759. http://dx.doi.org/10.3109/02688699409101194

[11] Kikuchi, K. and Kowada, M. (1994) Anterior Fossa Dural Arteriovenous Malformation Supplied by Bilateral Ethmoidal Arteries. Surgical Neurology, 41, 56-64. http://dx.doi.org/10.1016/0090-3019(94)90209-7

[12] Yoshimoto, H., Yukawa, O., Aoyama, H., Maeda, H. and Uozumi, T. (1993) Intracerebral Arteriovenous Malformation Fed by the Anterior Ethmoidal Artery-Case Report. Neurologia Medico-Chirurgica (Tokyo), 33, 246-250. http://dx.doi.org/10.2176/nmc.33.246

[13] Reul, J., Thron, A., Laborde, G. and Bruckmann, H. (1993) Dural Arteriovenous Malformations at the Base of the Anterior Cranial Fossa: Report of Nine Cases. Neuroradiology, 35, 388-393. http://dx.doi.org/10.1007/BF00588378

[14] Deshmukh, V.R., Chang, S., Albuquerque, F.C., McDougall, C.G. and Spetzler, R.F. (2005) Bilateral Ethmoidal Dural Arteriovenous Fistulae: A Previously Unreported Entity: Case Report. Neurosurgery, 57, E809. 
[15] Nakagawa, K., Takasato, Y. and Ito, Y. (1994) A Case of Dural Arteriovenous Malformation in the Anterior Cranial Fossa Presenting with Intracranial Hemorrhage. Brain and Nerve, 46, 387-391.

[16] Geibprasert, S., Pereira, V., Krings, T., Jiarakongmun, P., Toulgoat, F., Pongpech, S. and Lasjaunias, P. (2008) Dural Arteriovenous Shunts: A New Classification of Craniospinal Epidural Venous Anatomical Bases and Clinical Correlations. Stroke, 39, 2783-2794. http://dx.doi.org/10.1161/STROKEAHA.108.516757

[17] Awad, I.A., Little, J.R., Akarawi, W.P. and Ahl, J. (1990) Intracranial Dural Arteriovenous Malformations: Factors Predisposing to an Aggressive Neurological Course. Journal of Neurosurgery, 72, 839-850. http://dx.doi.org/10.3171/jns.1990.72.6.0839

[18] van Dijk, J.M., ter Brugge, K.G., Willinsky, R.A. and Wallace, M.C. (2002) Clinical Course of Cranial Dural Arteriovenous Fistulas with Long-Term Persistent Cortical Venous Reflux. Stroke, 33, 1233-1236. http://dx.doi.org/10.1161/01.STR.0000014772.02908.44

[19] Strom, R.G., Botros, J.A., Refai, D., Moran, C.J., Cross 3rd, D.T., Chicoine, M.R., Crubb Jr., R.L., Rich, K.M., Dacey Jr., R.G., Derdeyn, C.P. and Zipfel, G.J. (2009) Cranial Dural Arteriovenous Fistulae: Asymptomatic Cortical Venous Drainage Portends Less Aggressive Clinical Course. Neurosurgery, 64, 241-247, Discussion 247-248. http://dx.doi.org/10.1227/01.NEU.0000338066.30665.B2

[20] Jamous, M.A., Satoh, K., Satomi, J., Matsubara, S., Nakajima, N., Uno, M. and Nagahiro, S. (2004) Detection of Enlarged Cortical Vein by Magnetic Resonance Imaging Contributes to Early Diagnosis and Better Outcome for Patients with Anterior Cranial Fossa Dural Arteriovenous Fistula. Neurologia Medico-Chirurgica (Tokyo), 44, 516-520, Discussion 520-521. http://dx.doi.org/10.2176/nmc.44.516

[21] Bitoh, S., Nakagawa, H., Arita, N. and Fujiwara, M. (1981) Dural Arteriovenous Malformation in the Anterior Fossa: Case Report. Neurologia Medico-Chirurgica (Tokyo), 21, 131-134. http://dx.doi.org/10.2176/nmc.21.131

[22] Yamasaki, F., Hotta, T., Taniguchi, E., Eguchi, K., Hashizume, A., Kodama, Y. and Yuki, K. (1995) A Case of Dural Arteriovenous Malformation in the Anterior Fossa Associated with an Occlusion of the Unilateral Middle Cerebral Artery with Moyamoya Phenomenon. No Shinkei Geka, 23, 603-607.

[23] Ishikawa, T., Houkin, K., Tokuda, K., Kawaguchi, S. and Kashiwaba, T. (1997) Development of Anterior Cranial Fossa Dural Arteriovenous Malformation Following Head Trauma: Case Report. Journal of Neurosurgery, 86, 291-293. http://dx.doi.org/10.3171/jns.1997.86.2.0291

[24] Im, S.H., Oh, C.W. and Han, D.H. (2004) Surgical Management of an Unruptured Dural Arteriovenous Fistula of the Anterior Cranial Fossa: Natural History for 7 Years. Surgical Neurology, 62, 72-75, Discussion 75. http://dx.doi.org/10.1016/j.surneu.2003.07.018

[25] Murakami, K., Matsumoto, K., Numagami, Y., Tomita, T. and Nishijma, M. (2005) A Case of Secondary Anterior Fossa Dural Arteriovenous Fistula Following Posterior Fossa Craniotomy. No Shinkei Geka, 33, 1101-1105.

[26] Hashiguchi, A., Mimata, C., Ichimura, H., Morioka, M. and Kuratsu, J. (2007) Venous Aneurysm Development Associated with a Dural Arteriovenous Fistula of the Anterior Cranial Fossa with Devastating Hemorrhage-Case Report. Neurologia Medico-Chirurgica (Tokyo), 47, 70-73. http://dx.doi.org/10.2176/nmc.47.70

[27] Tanei, T., Fukui, K., Wakabayashi, K., Mitsui, Y., Inoue, N. and Watanabe, M. (2008) Dural Arteriovenous Fistula in the Anterior Cranial Fossa: Four Case Reports. Neurologia Medico-Chirurgica (Tokyo), 48, 560-563. http://dx.doi.org/10.2176/nmc.48.560

[28] Cognard, C., Gobin, Y.P., Pierot, L., Bailly, A.L., Houdart, E., Casasco, A., Chiras, J. and Merland, J.J. (1995) Cerebral Dural Arteriovenous Fistulas: Clinical and Angiographic Correlation with a Revised Classification of Venous Drainage. Radiology, 194, 671-680. http://dx.doi.org/10.1148/radiology.194.3.7862961

[29] Defreyne, L., Vanlangenhove, P., Vandekerckhove, T., Deschrijver, I., Sieben, G., Klaes, R. and Kunnen, M. (2000) Transvenous Embolization of a Dural Arteriovenous Fistula of the Anterior Cranial Fossa: Preliminary Results. American Journal of Neuroradiology, 21, 761-765.

[30] Agid, R., Terbrugge, K., Rodesch, G., Andersson, T. and Soderman, M. (2009) Management Strategies for Anterior Cranial Fossa (Ethmoidal) Dural Arteriovenous Fistulas with an Emphasis on Endovascular Treatment. Journal of Neurosurgery, 110, 79-84. http://dx.doi.org/10.3171/2008.6.17601

[31] Lv, X., Li, Y. and Wu, Z. (2008) Endovascular Treatment of Anterior Cranial Fossa Dural Arteriovenous Fistula. Neuroradiology, 50, 433-437. http://dx.doi.org/10.1007/s00234-007-0346-6

[32] Li, C., Wu, Z., Yang, X., Li, Y., Jiang, C. and He, H. (2014) Transarterial Treatment with Onyx of Cognard Type IV Anterior Cranial Fossa Dural Arteriovenous Fistulas. Journal of Neurointerventional Surgery, 6, 115-120. http://dx.doi.org/10.1136/neurintsurg-2012-010641 